\title{
Falls in nursing home residents receiving pharmacotherapy for anemia
}

\author{
This article was published in the following Dove Press journal: \\ Clinical Interventions in Aging \\ 4 October 2012 \\ Number of times this article has been viewed
}

\author{
Gregory Reardon' \\ Naushira Pandya ${ }^{2}$ \\ Robert A Bailey ${ }^{3}$ \\ 'Informagenics, LLC and The Ohio \\ State University College of Pharmacy, \\ Columbus, OH, USA; 'Department \\ of Geriatrics, Nova Southeastern \\ University College of Osteopathic \\ Medicine, Ft Lauderdale, FL, USA; \\ 3anssen Scientific Affairs, LLC, \\ Horsham, PA, USA
}

Purpose: Falls are common among nursing home residents and have potentially severe consequences, including fracture and other trauma. Recent evidence suggests anemia may be independently related to these falls. This study explores the relationship between the use of anemia-related pharmacotherapies and falls among nursing home residents.

Methods: Forty nursing homes in the United States provided data for analysis. All incidents of falls over the 6-month post-index follow-up period were used to identify the outcomes of falls ( $\geq 1$ fall) and recurrent falls ( $>1$ fall). Logistic regression was used to analyze the relationship between falls and recurrent falls with each of the anemia pharmacotherapies after adjusting for potential confounders.

Results: A total of 632 residents were eligible for analysis. More than half (57\%) of residents were identified as anemic (hemoglobin $<12 \mathrm{~g} / \mathrm{dL}$ females, or $<13 \mathrm{~g} / \mathrm{dL}$ males). Of anemic residents, $50 \%$ had been treated with one or more therapies (14\% used vitamin B12, 10\% folic acid, $38 \%$ iron, $0.3 \%$ darbepoetin alfa [DARB], and $1.3 \%$ epoetin alfa [EPO]). Rates of falls/ recurrent falls were $33 \% / 18 \%$ for those receiving vitamin B12, 40\%/16\% for folic acid, $27 \% / 14 \%$ for iron, $38 \% / 8 \%$ for DARB, $18 \% / 2 \%$ for EPO, and $22 \% / 11 \%$ for those receiving no therapy. In the adjusted models, use of EPO or DARB was associated with significantly lower odds of recurrent falls (odds ratio $=0.06 ; P=0.001$ ). Other significant covariates included psychoactive medication use, age 75-84 years, age $85+$ years, worsened balance score, and chronic kidney disease $(P<0.05$ for all).

Conclusion: Only half of the anemic residents were found to be using anemia therapy (vitamin B12, folic acid, or iron). There is little evidence to support an association between the use of vitamin B12, folic acid, or iron in reducing the rates of falls and recurrent falls in nursing homes. Reduced odds of recurrent falls were observed for DARB or EPO users.

Keywords: anemia, fall, hemoglobin, long-term care, nursing home, pharmacotherapy

\section{Introduction}

Anemia is a common condition in the nursing home. Using World Health Organization (WHO $)^{1}$ criteria to define anemia $(<12 \mathrm{~g} / \mathrm{dL}$ for nonpregnant females and $<13 \mathrm{~g} / \mathrm{dL}$ for adult males), rates of anemia in the United States (US) were found to be $40 \%{ }^{2}$ in one nursing home, $48 \%{ }^{3}$ in five nursing homes, $56 \%{ }^{4}$ across 40 nursing homes, and $60 \%$ in one nursing home chain. ${ }^{5}$ In Italy, De Maria et $\mathrm{al}^{6}$ reported an anemia prevalence rate of $50 \%$ in a chart review of 441 female nursing home residents.

Anemia has been linked to increased rates of mortality in nursing homes. After adjusting for age, sex, functional disability, key conditions, and fall history, Kiely and Flacker ${ }^{7}$ showed that anemia in female residents was associated with a 1.98 relative risk
Correspondence: Gregory Reardon Informagenics, LLC, $450 \mathrm{~W}$ Wilson Bridge Rd Suite 340, Worthington, $\mathrm{OH}, 43085$ USA

Tel +l 6148471900

Fax +l 614573 7129

Email greardon@informagenics.com which permits unrestricted noncommercial use, provided the original work is properly cited. 
of mortality. De Maria et $\mathrm{al}^{6}$ found that female nursing home residents with the combined presence of heart disease and WHO-defined anemia had a 3.35-times greater age-adjusted risk of death compared to residents with an absence of either condition. Van Dijk et $\mathrm{al}^{8}$ found that anemia predicted a $17 \%$ increase in the adjusted odds of resident mortality, though this relationship disappeared when activities of daily living score was included. Berry et $\mathrm{al}^{9}$ found a $60 \%$ higher adjusted risk of mortality following hip fracture in residents who had anemia prior to the fracture.

Falls are common and have potentially serious consequences in the nursing home. In a review of sixteen epidemiologic reports, Rubenstein et $\mathrm{al}^{10}$ reported that the mean fall incidence in long-term care facilities ( 1.5 falls per bed per year, not age-adjusted) was approximately three times the rate found in the community. Of these falls, $4 \%$ were shown to result in fracture. Serious injuries such as head trauma, soft-tissue injuries, and severe lacerations occurred in a mean of $11 \%$ of all falls. Nursing home residents also have a substantially higher rate of hip fracture and a higher mortality rate after hip fracture than individuals in the community. ${ }^{10}$

Empirical evidence suggests that anemia may be independently related to falls among nursing home residents. In a combined group of 36 nursing home residents and 109 community dwellers hospitalized for hip fracture, $30 \%$ of anemic patients were found to have a history of falls compared to only $13 \%$ in the nonanemic group $(P=0.028) .{ }^{11}$ Using an adjusted model, these authors found a $45 \%$ decreased risk of falls for every $1.0 \mathrm{~g} / \mathrm{dL}$ increase in $\mathrm{Hb}$ $(P=0.005)$. Pandya et $\mathrm{al}^{4}$ observed that hemoglobin $(\mathrm{Hb})$ level was associated with subsequent falls (one or more falls over the 6-month follow-up) and recurrent falls (two or more falls over the same period); the adjusted risk for falls and for recurrent falls were lower by $19 \%(P=0.001)$ and $24 \%$ $(P=0.001)$, respectively, for each incremental $\mathrm{g} / \mathrm{dL}$ unit increase of hemoglobin. ${ }^{4}$

Anemia in the nursing home may be due to one of several potential causes. In one study of 60 anemic nursing home residents, ${ }^{12}$ chart reviews revealed that anemia causes were idiopathic $(45 \%)$ or due to iron deficiency (23\%), chronic disease $(13 \%)$, renal insufficiency $(10 \%)$, or other reasons $(8 \%)$. Anemia appears to be a frequent complication of chronic kidney disease (CKD). This is mainly due to inadequate production of endogenous erythropoietin, which leads to decreased stimulation of the bone marrow to produce red blood cells; anemia of CKD has been shown to develop early and worsen with progressive renal insufficiency, particularly when glomerular filtration rate falls to $50 \%$ of the normal range. ${ }^{13,14}$ In the elderly, vitamin B12 and folic acid nutritional deficiencies are common pathological causes of macrocytosis and are associated with the development of associated macrocytic anemia. ${ }^{15}$ Other conditions such as alcoholism may also be important causes of anemia in the nursing home.

The decision to treat anemia in the long-term care setting should be based on the risks versus benefits of treatment. ${ }^{16}$ Anemia treatment should be guided by appropriate evaluation to determine the underlying cause. Directed therapies to treat underlying causes of anemia include vitamin B12, folic acid, and iron administration. Erythropoiesis-stimulating agents (ESA) (eg, epoetin alfa [EPO] or darbepoetin alfa [DARB]) are also used, but less commonly. ESA therapy is indicated for the treatment of anemia due to CKD and due to the effect of concomitantly administered chemotherapy in metastatic, nonmyeloid malignancies. EPO is also indicated to treat anemia in human immunodeficiency virus-infected patients on zidovudine, as well as to reduce allogeneic red blood cell transfusions in patients undergoing elective, noncardiac, nonvascular surgery. ${ }^{17,18}$

No study to date has evaluated the relationship of anemia pharmacotherapy and specific clinical endpoints in the long-term care setting. Although examining the proximate relationship between the use of specific pharmacotherapies and subsequent improvement of $\mathrm{Hb}$ levels might be practical in some institutional settings such as hospitals, in long-term care settings, post-index $\mathrm{Hb}$ levels are examined infrequently, and blood may be drawn less often among less severely anemic residents. Falls, however, are important events in the nursing home that are expected to be consistently charted when they occur. The primary purpose of the present study was to investigate the potential independent association between the use of vitamin B12, folic acid, iron, EPO, and DARB therapy and the rates of falls and recurrent falls over a 6-month observation period after adjusting for the effect of underlying differences in baseline $\mathrm{Hb}$, resident characteristics, and propensity score for receiving ESA.

\section{Methods}

\section{Residents and study design}

An earlier analysis of a subset of the data used in the current study described the prevalence of anemia and its association with falls in nursing home residents. ${ }^{4}$ Study data were obtained by a professional data collection service (Synovate Healthcare, London, UK). Nursing homes across 
the US were recruited for study participation through a mass mailing. Institutions were excluded from participation that were rehabilitation centers, dialysis clinics, assisted living homes, or adult day care centers.

Nurses employed within the nursing homes were directed by the data collection service through written instruction and help-desk support to: (1) perform a systematic random sampling of all patient charts, (2) review charts on-site to determine whether eligibility inclusion criteria were met, (3) record abstracted information from eligible patient charts onto de-identified data collection forms, and (4) send completed data collection forms to the data collection service for data entry. Systematic random sampling was initiated by randomly selecting a single resident and evaluating his/her eligibility for inclusion. Subsequently, every third chart was selected and evaluated for eligibility until approximately 15-20 eligible residents were identified and had data forms completed. Eligible residents included those who: (1) had an $\mathrm{Hb}$ level reported during the data uptake period of January 1 , 2004-June 30, 2005 and (2) were at least 18 years of age. The earliest $\mathrm{Hb}$ level obtained during the uptake period was identified as the index $\mathrm{Hb}$ level. The date of this level was the index date. Eligible residents were further required during the 6-month post-index follow-up period to: (3) have a recorded serum creatinine level within 6 months of the index date, and (4) for a minimum of 6 months subsequent to the index date, have been a resident of the facility (hospitalizations and readmissions permitted) and (5) not have received dialysis.

The initial sample of residents constituted the first stratum for the current study. Anticipating a very low utilization rate for EPO and DARB therapy, each of the 40 participating nursing homes was directed by the data collection service in the initial data request to separately sample only those residents receiving DARB or EPO (second stratum). With the exception of the additional eligibility requirement of DARB or EPO use, remaining selection criteria and data provided for eligible residents used in the first sampling stratum were unchanged for this second sampling stratum.

All data received by researchers were in a deidentified form in accordance with Health Insurance Portability and Accountability Act safe-harbor requirements and did not require institutional review board approval. Data were collected from medical charts, labs, pharmacy records, and the most recent Minimum Data Set (MDS) version $2.0 ;{ }^{19}$ this included resident demographics, serum creatinine, medical history, current medical conditions, concurrent medications, anemia therapy, activities of daily living (ADL, MDS section G1 Physical Functioning and Structural Problems), and balance tests (MDS section G3). Residents' clinical parameters and any reported falls and hospital admissions were followed in the chart for 6 months after the index date.

\section{Statistical analysis}

From the reported data of each eligible resident, study researchers used algorithms to calculate estimated glomerular filtration rate (eGFR), ADL score, and balance score. eGFR was calculated from age, sex, race, and serum creatinine (closest in time to the index $\mathrm{Hb}$ ) using the four-variable Modification of Diet in Renal Disease algorithm: ${ }^{20,21}$

eGFR $\left(\mathrm{mL} / \mathrm{min} / 1.73 \mathrm{~m}^{2}\right)=186 \times(\mathrm{Scr})^{-1.154} \times(\text { Age })^{-0.203}$ $\times(0.742$ if female $) \times(1.21$ if African-American $)$.

Performance ratings on seven ADL items from MDS section G1 were used to calculate a single summary ADL score by using the methodology of Carpenter et al. ${ }^{22}$ This is a 0-28 point scale where higher scores indicate worsened ADL performance. Ratings for the two balance items "balance while standing" and "balance while sitting" from MDS section G3 were summed to create a $0-6$ point scale, where higher scores indicate worsened balance performance.

To avoid overstating the statistical confidence of study estimates, the stratified sampling method described above (first stratum = sample of all residents; second stratum $=$ separate sample of EPO/DARB users only) necessitated the use of sampling weights for analysis to correctly specify standard errors when pooling data from both strata. All analyses of descriptive statistics and logistic regression models used the svy family of survey data procedures in Stata 8.0 (StataCorp, College Station, TX) to incorporate these sampling weights when deriving estimates. Since the multivariate models employed required complete data for all retained residents, values for missing data in these variables were imputed separately for each stratum from a regression model using 20 baseline resident characteristics.

All incidents of falls over the 6-month post-index follow-up period were used to assign residents to falls (one or more falls) and recurrent falls (more than one fall) outcome classifications. Logistic regression was used to analyze the relationship between the independent effect of vitamin B12, folic acid, iron, and DARB or EPO therapy with falls, and with recurrent falls, after adjusting for index $\mathrm{Hb}$, explanatory variables presumed to be related to falls, concurrent use of more than one of these therapies, and propensity to receive DARB or EPO. DARB users were combined with EPO users due to the low number of DARB users sampled $(n=13)$. In the logistic models, 26 covariates in addition to the propensity 
Table I All resident characteristics

\begin{tabular}{|c|c|c|c|c|c|c|c|}
\hline & $\begin{array}{l}\text { Vitamin BI2 } \\
(n=82)\end{array}$ & $\begin{array}{l}\text { Folic acid } \\
(n=56)\end{array}$ & $\begin{array}{l}\text { Iron } \\
(n=194)\end{array}$ & $\begin{array}{l}\text { DARB } \\
(n=13)\end{array}$ & $\begin{array}{l}\text { EPO } \\
(n=55)\end{array}$ & $\begin{array}{l}\text { No therapy } \\
(n=348)\end{array}$ & $\begin{array}{l}\text { All residents } \\
(n=632)\end{array}$ \\
\hline \multicolumn{8}{|l|}{ Demographics } \\
\hline Age, years (mean, SD) & $82.1(1.4)$ & $77.3(1.9)$ & $82.7(0.73)$ & $74.2(3.1)$ & $81.7(1.3)$ & $80.3(0.7 I)$ & $8 I .0(0.5 I)$ \\
\hline \multicolumn{8}{|l|}{ Age category } \\
\hline$<65$ years & $8 \%$ & $17 \%$ & $5 \%$ & $15 \%$ & $4 \%$ & $12 \%$ & $10 \%$ \\
\hline $65-74$ years & $8 \%$ & $19 \%$ & $13 \%$ & $31 \%$ & $15 \%$ & $10 \%$ & $11 \%$ \\
\hline $75-84$ years & $34 \%$ & $29 \%$ & $36 \%$ & $31 \%$ & $45 \%$ & $34 \%$ & $34 \%$ \\
\hline $85+$ years & $49 \%$ & $35 \%$ & $47 \%$ & $23 \%$ & $36 \%$ & $44 \%$ & $45 \%$ \\
\hline Female & $63 \%$ & $55 \%$ & $67 \%$ & $46 \%$ & $73 \%$ & $73 \%$ & $70 \%$ \\
\hline African-American & $10 \%$ & $21 \%$ & $11 \%$ & $0 \%$ & $18 \%$ & $12 \%$ & $12 \%$ \\
\hline \multicolumn{8}{|l|}{ Mobility } \\
\hline ADL score $(\text { mean, } S D)^{\mathrm{a}}$ & I $5.7(0.86)$ & I7.0 (I.I) & $15.4(0.6 \mid)$ & $16.0(1.7)$ & I4.7 (I.0) & I4.7 (0.45) & $15.0(0.34)$ \\
\hline Balance score (mean, SD) ${ }^{\mathrm{a}}$ & $2.6(0.23)$ & $3.2(0.29)$ & $3.0(0.15)$ & $2.8(0.4 I)$ & $2.8(0.27)$ & $2.7(0.11)$ & $2.8(0.08)$ \\
\hline \multicolumn{8}{|l|}{ Hemoglobin and renal function } \\
\hline Hemoglobin level (g/dL, mean, SD) & II.7 (0.18) & II.0 (0.25) & $10.9(0.12)$ & $10.4(0.41)$ & $10.3(0.22)$ & $12.3(0.09)$ & I I.9 (0.07) \\
\hline \multicolumn{8}{|l|}{ Hemoglobin level $(g / d L)$} \\
\hline $13+g / d L$ & $20 \%$ & $9 \%$ & $8 \%$ & $8 \%$ & $4 \%$ & $35 \%$ & $26 \%$ \\
\hline 12 to $<13 \mathrm{~g} / \mathrm{dL}$ & $30 \%$ & $25 \%$ & $20 \%$ & $8 \%$ & $5 \%$ & $23 \%$ & $23 \%$ \\
\hline II to $<12 \mathrm{~g} / \mathrm{dL}$ & $18 \%$ & $19 \%$ & $18 \%$ & $31 \%$ & $18 \%$ & $18 \%$ & $19 \%$ \\
\hline 10 to $<\mathrm{II} g / d \mathrm{~L}$ & $12 \%$ & $17 \%$ & $26 \%$ & $15 \%$ & $24 \%$ & $14 \%$ & $17 \%$ \\
\hline$<10 \mathrm{~g} / \mathrm{dL}$ & $20 \%$ & $29 \%$ & $27 \%$ & $38 \%$ & $49 \%$ & $9 \%$ & $15 \%$ \\
\hline Anemic (WHO definition) & $61 \%$ & $77 \%$ & $78 \%$ & $85 \%$ & $93 \%$ & $47 \%$ & $57 \%$ \\
\hline \multicolumn{8}{|l|}{$\mathrm{mL} / \mathrm{min} / \mathrm{I} .73 \mathrm{~m}^{2, \mathrm{a}}$} \\
\hline Low eGFR (MDRD), & $54 \%$ & $57 \%$ & $49 \%$ & $62 \%$ & $58 \%$ & $41 \%$ & $44 \%$ \\
\hline \multicolumn{8}{|l|}{$<60 \mathrm{~mL} / \mathrm{min} / 1.73 \mathrm{~m}^{2}$} \\
\hline \multicolumn{8}{|l|}{ Diseases and conditions } \\
\hline Chronic kidney disease $^{\mathrm{b}}$ & $21 \%$ & $31 \%$ & $14 \%$ & $54 \%$ & $27 \%$ & $12 \%$ & $14 \%$ \\
\hline Congestive heart failure & $40 \%$ & $43 \%$ & $37 \%$ & $38 \%$ & $38 \%$ & $34 \%$ & $35 \%$ \\
\hline Coronary heart disease & $23 \%$ & $31 \%$ & $24 \%$ & $23 \%$ & $24 \%$ & $19 \%$ & $21 \%$ \\
\hline Diabetes (including insulin-dependent) & $33 \%$ & $43 \%$ & $37 \%$ & $54 \%$ & $42 \%$ & $29 \%$ & $32 \%$ \\
\hline Hypertension & $77 \%$ & $79 \%$ & $71 \%$ & $77 \%$ & $80 \%$ & $66 \%$ & $69 \%$ \\
\hline Hypotension & $4 \%$ & $7 \%$ & $3 \%$ & $0 \%$ & $2 \%$ & $1 \%$ & $2 \%$ \\
\hline Cerebral vascular disease & $35 \%$ & $38 \%$ & $27 \%$ & $15 \%$ & $25 \%$ & $30 \%$ & $29 \%$ \\
\hline Peripheral vascular disease & $0 \%$ & $2 \%$ & $4 \%$ & $0 \%$ & $7 \%$ & $6 \%$ & $5 \%$ \\
\hline Dementia & $51 \%$ & $64 \%$ & $53 \%$ & $38 \%$ & $38 \%$ & $54 \%$ & $53 \%$ \\
\hline Cancer & $7 \%$ & $14 \%$ & $12 \%$ & $8 \%$ & $20 \%$ & $7 \%$ & $9 \%$ \\
\hline Parkinson's disease & $12 \%$ & $3 \%$ & $8 \%$ & $8 \%$ & $5 \%$ & $7 \%$ & $7 \%$ \\
\hline COPD & $19 \%$ & $21 \%$ & $20 \%$ & $15 \%$ & $20 \%$ & $23 \%$ & $22 \%$ \\
\hline Asthma & $1 \%$ & $5 \%$ & $4 \%$ & $0 \%$ & $5 \%$ & $5 \%$ & $4 \%$ \\
\hline Osteoarthritis & $55 \%$ & $38 \%$ & $46 \%$ & $54 \%$ & $25 \%$ & $40 \%$ & $43 \%$ \\
\hline Rheumatoid arthritis & $4 \%$ & $7 \%$ & $6 \%$ & $0 \%$ & $7 \%$ & $4 \%$ & $4 \%$ \\
\hline Neurological disease & $15 \%$ & $21 \%$ & $16 \%$ & $15 \%$ & II\% & $21 \%$ & $20 \%$ \\
\hline \multicolumn{8}{|l|}{ Current medications } \\
\hline Diuretic use & $48 \%$ & $45 \%$ & $45 \%$ & $62 \%$ & $35 \%$ & $44 \%$ & $45 \%$ \\
\hline Psychoactive medication use & $77 \%$ & $84 \%$ & $64 \%$ & $92 \%$ & $73 \%$ & $68 \%$ & $68 \%$ \\
\hline Beta blocker use & $31 \%$ & $36 \%$ & $36 \%$ & $15 \%$ & $38 \%$ & $24 \%$ & $28 \%$ \\
\hline \multicolumn{8}{|l|}{ Anemia therapy } \\
\hline Vitamin BI2 (cyanocobalamin) & $100 \%$ & $51 \%$ & $14 \%$ & $23 \%$ & $11 \%$ & $0 \%$ & $13 \%$ \\
\hline Folic acid & $30 \%$ & $100 \%$ & $11 \%$ & $23 \%$ & $20 \%$ & $0 \%$ & $8 \%$ \\
\hline Iron & $30 \%$ & $39 \%$ & $100 \%$ & $31 \%$ & $62 \%$ & $0 \%$ & $28 \%$ \\
\hline DARB (darbepoetin alfa) & $0 \%$ & $1 \%$ & $0 \%$ & $100 \%$ & $0 \%$ & $0 \%$ & $0 \%$ \\
\hline EPO (epoetin alfa) & $1 \%$ & $2 \%$ & $2 \%$ & $0 \%$ & $100 \%$ & $0 \%$ & $1 \%$ \\
\hline No therapy & $0 \%$ & $0 \%$ & $0 \%$ & $0 \%$ & $0 \%$ & $100 \%$ & $61 \%$ \\
\hline
\end{tabular}

Notes: Of the 632 people studied, many used more than one anemia therapy. All statistics above estimated using sampling weights. ${ }^{2}$ Some residents had missing values for eGFR, ADL Score, or Balance Score. For these, values were imputed from remaining characteristics to enable their inclusion in the regression models; ${ }^{b}$ where a diagnosis for chronic kidney disease was identified in the resident's chart.

Abbreviations: ADL, activities of daily living; COPD, chronic obstructive pulmonary disease; DARB, darbepoetin; eGFR, estimated glomerular filtration rate; EPO, epoetin alfa; MDRD, Modification of Diet in Renal Disease; SD, standard deviation. 
score were included (Table 1). Hb level was converted to one of five ranges ( $\geq 13 \mathrm{~g} / \mathrm{dL}, 12$ to $<13,11$ to $<12,10$ to $<11,<10$ ).

To adjust for potential confounding factors by disease severity associated with ESA treatment, propensity scores for receiving DARB or EPO therapy were estimated for each resident by including the following factors in an unweighted propensity model: demographics (age group, sex, AfricanAmerican race), index $\mathrm{Hb}$, eGFR $<60 \mathrm{~mL} / \mathrm{min} / 1.73 \mathrm{~m}^{2}$, likely causes of anemia (blood loss, chronic disease, folic acid deficiency, iron deficiency, malignancy, pernicious anemia, chronic kidney disease), and other conditions potentially related to selection of anemia treatment (gastrointestinal bleeding, inflammatory bowel disease, congestive heart failure, coronary heart disease, diabetes, cancer). The resulting propensity model had an explanatory power $\left(\mathrm{r}^{2}\right)$ of 0.24 $(P<0.001$, Chi-square $)$.

\section{Results}

Forty nursing homes who responded to the invitation provided usable data for analysis. These included institutions located in the East, Midwest, Central Plains, Northwest, South, and Hawaii. ${ }^{4}$ Of the 579 eligible residents identified in the first stratum (who all were determined to be nonusers of EPO or DARB), 564 met the minimal criteria for data completeness (had no missing values for age, sex, race, and index hemoglobin level) and were retained for final analysis. All 68 residents in the second stratum met minimal criteria for data completeness. In both strata, some residents were found to be missing data for some items used to calculate ADL $(n=36)$ or balance score $(n=37)$ or for the serum creatinine used to calculate eGFR level $(n=15)$. For these variables, missing values were imputed from a multiple linear regression model (Stata Impute procedure) as described above.

Table 1 shows estimates of key resident characteristics for users of each of the anemia therapies. Mean age of all residents was 81.0 years. Users of iron were older (82.7 years), while users of DARB (74.2 years) and folic acid (77.3 years) were younger. Females accounted for $70 \%$ of all residents. African-Americans comprised $12 \%$ of all residents. More than half (57\%) of all residents were identified as anemic (WHO definition) based on their index $\mathrm{Hb}$ (Table 1). Of anemic residents, $50 \%$ were using one or more of three therapies; $14 \%$ used vitamin B12, $10 \%$ used folic acid, and $38 \%$ used iron. Although $15 \%$ of all residents had the lowest $\mathrm{Hb}$ level $(<10 \mathrm{~g} / \mathrm{dL}), 49 \%$ of EPO and $38 \%$ of DARB users fell into this category.

Of all residents with eGFR $<60 \mathrm{~mL} / \mathrm{min} / 1.73 \mathrm{~m}^{2}$, $61 \%$ were anemic. Mean eGFR for all residents was $68 \mathrm{~mL} / \mathrm{min} / 1.73 \mathrm{~m}^{2}$, but was lower for users of each of the pharmacotherapies, including $15 \mathrm{~mL} / \mathrm{min} / 1.73 \mathrm{~m}^{2}$ points lower for EPO and $10 \mathrm{~mL} / \mathrm{min} / 1.73 \mathrm{~m}^{2}$ points lower for folic acid users. Documented chronic kidney disease was also higher than average for users of all pharmacotherapies except iron.

Concurrent usage of anemia pharmacotherapies was common, particularly with concurrent use of vitamin B12 or iron in folic acid users (51\% and 39\% concurrent use respectively), concurrent use of folic acid and iron in vitamin B12 users (30\% concurrent use each), and iron in EPO users (62\% concurrent use).

Table 2 shows unadjusted rates for falls and recurrent falls for each of the therapy users. Of all residents, $24 \%$ fell one or more times and $12 \%$ fell two or more times during the

Table 2 All resident rates of falls and recurrent falls

\begin{tabular}{|c|c|c|c|c|c|c|c|c|}
\hline Falling event & $\begin{array}{l}\text { Hemoglobin level } \\
\text { (g/dL) }\end{array}$ & $\begin{array}{l}\text { Vitamin B I } \\
(n=82)\end{array}$ & $\begin{array}{l}\text { Folic acid } \\
(n=56)\end{array}$ & $\begin{array}{l}\text { Iron } \\
(n=194)\end{array}$ & $\begin{array}{l}\text { DARB } \\
(n=13)\end{array}$ & $\begin{array}{l}\text { EPO } \\
(n=55)\end{array}$ & $\begin{array}{l}\text { No therapy } \\
(n=348)\end{array}$ & $\begin{array}{l}\text { All residents }{ }^{\mathrm{a}} \\
(\mathrm{n}=632)\end{array}$ \\
\hline Fell one or & All levels & $33 \%$ & $40 \%$ & $27 \%$ & $38 \%$ & $18 \%$ & $22 \%$ & $24 \%$ \\
\hline \multirow[t]{5}{*}{ more times } & $13+$ & $13 \%$ & $0 \%$ & $8 \%$ & $100 \%$ & $50 \%$ & $13 \%$ & $12 \%$ \\
\hline & 12 to $<13$ & $32 \%$ & $55 \%$ & $25 \%$ & $0 \%$ & $0 \%$ & $23 \%$ & $24 \%$ \\
\hline & II to $<12$ & $31 \%$ & $25 \%$ & $11 \%$ & $25 \%$ & $20 \%$ & $30 \%$ & $25 \%$ \\
\hline & 10 to $<11$ & $44 \%$ & $70 \%$ & $38 \%$ & $0 \%$ & $15 \%$ & $27 \%$ & $34 \%$ \\
\hline & $<10$ & $51 \%$ & $33 \%$ & $33 \%$ & $60 \%$ & $19 \%$ & $38 \%$ & $35 \%$ \\
\hline Fell repetitively & All levels & $18 \%$ & $16 \%$ & $14 \%$ & $8 \%$ & $2 \%$ & $11 \%$ & $12 \%$ \\
\hline \multirow[t]{5}{*}{$(>I$ fall $)$} & $13+$ & $0 \%$ & $0 \%$ & $0 \%$ & $0 \%$ & $0 \%$ & $6 \%$ & $5 \%$ \\
\hline & 12 to $<13$ & $14 \%$ & $9 \%$ & $16 \%$ & $0 \%$ & $0 \%$ & $11 \%$ & $11 \%$ \\
\hline & II to $<12$ & $31 \%$ & $24 \%$ & $7 \%$ & $0 \%$ & $0 \%$ & $9 \%$ & $11 \%$ \\
\hline & 10 to $<11$ & $22 \%$ & $28 \%$ & $19 \%$ & $0 \%$ & $0 \%$ & $18 \%$ & $18 \%$ \\
\hline & $<10$ & $28 \%$ & $16 \%$ & $16 \%$ & $20 \%$ & $4 \%$ & $19 \%$ & $18 \%$ \\
\hline
\end{tabular}

Notes: a Of the 632 studied, many used more than one anemia therapy. All statistics above estimated using sampling weights. Abbreviations: DARB, darbepoetin; EPO, epoetin alfa. 
6-month follow period. Rates of falls across anemia therapy users were 33\% for those receiving vitamin B12, 40\% for folic acid, $27 \%$ for iron, $38 \%$ for DARB, 18\% for EPO, and $22 \%$ for those receiving no therapy. Rates of recurrent falls were $18 \%$ for vitamin B12 users, $16 \%$ for folic acid, 14\% for iron, $8 \%$ for DARB, $2 \%$ for EPO, and $11 \%$ for those receiving no therapy. For all residents, rates of falls and recurrent falls generally increased with declining $\mathrm{Hb}$ level, particularly between $\mathrm{Hb}$ levels of 11 to $<13 \mathrm{~g} / \mathrm{dL}$ and $<11 \mathrm{~g} / \mathrm{dL}$ when compared to the reference $\mathrm{Hb} 13+\mathrm{g} / \mathrm{dL}$. However, this relationship was less consistent within users of each of the five pharmacotherapies.

Table 3 shows the adjusted logistic regression results for falls. Lower $\mathrm{Hb}$ levels were associated with higher odds of falls compared to the nonanemic $(\mathrm{Hb}=13+\mathrm{g} / \mathrm{dL})$ reference; the odds of falls were: $\mathrm{Hb}=12$ to $<13 \mathrm{~g} / \mathrm{dL}$ (odds ratio $[\mathrm{OR}]=2.18 ; P=0.024), 11$ to $<12 \mathrm{~g} / \mathrm{dL}(\mathrm{OR}=2.10$; $P=0.048), 10$ to $<11 \mathrm{~g} / \mathrm{dL}(\mathrm{OR}=3.58 ; P=0.001)$, and $<10 \mathrm{~g} / \mathrm{dL}(\mathrm{OR}=3.54 ; P=0.006)$. Of remaining covariates, only psychoactive medication use (which includes sedatives, hypnotics, antidepressants, and antipsychotics, $\mathrm{OR}=2.01 ; P=0.004)$ was significantly associated with increased odds of falling.

Table 4 shows results from the logistic regression for recurrent falls. Compared to the falls model, lower $\mathrm{Hb}$ level was also associated with higher odds of recurrent falls: $\mathrm{Hb}=12$ to $<13 \mathrm{~g} / \mathrm{dL}(\mathrm{OR}=2.84 P=0.043)$, 11 to $<12 \mathrm{~g} / \mathrm{dL}(\mathrm{OR}=2.21 ; P=$ not significant $[\mathrm{NS}])$, 10 to $<11 \mathrm{~g} / \mathrm{dL}(\mathrm{OR}=4.74 ; P=0.004)$, and $<10 \mathrm{~g} / \mathrm{dL}$ $(\mathrm{OR}=3.36 ; P=0.045)$. Similarly, psychoactive medication use $(\mathrm{OR}=2.58 ; P=0.013)$ had higher odds, and DARB or EPO therapy had lower odds of recurrent falls $(\mathrm{OR}=0.06$; $P=0.001)$. Other covariates significantly associated with recurrent falls included age $75-84$ years $(\mathrm{OR}=14.84$; $P=0.030)$, age $85+$ years $(\mathrm{OR}=14.25 ; P=0.031)$, poor balance score $(\mathrm{OR}=0.84 ; P=0.040)$, and chronic kidney disease $(\mathrm{OR}=2.23 ; P=0.031)$.

Since a large number of residents with apparent kidney disease were available, the logistic regression findings were replicated for falls and recurrent falls, adjusting for all covariates as before, but this time including only the subpopulation of residents with either documented CKD (MDS checkbox or ICD9 entry) or evidence of stage 3 or higher CKD $\left(\mathrm{eGFR}<60 \mathrm{~mL} / \mathrm{min} / 1.73 \mathrm{~m}^{2}\right)$. For the subpopulation of those with apparent kidney disease (Table 5), the odds of falls and recurrent falls were $\mathrm{OR}=0.64$; $P=\mathrm{NS}$ and $\mathrm{OR}=0.09 ; P=0.015$ for DARB or EPO users, respectively.

\section{Discussion}

Guidelines issued by the American Medical Directors Association for anemia in the long-term care practice setting $^{23}$ suggest that a detailed laboratory evaluation should be performed, including complete blood count, evaluation of red blood cell morphology, ferritin, serum iron, total iron-binding capacity, and serum folate and B12 levels, among other lab assessments as clinically indicated. Following these detailed findings, these same guidelines suggest targeted therapy depending on the specific type of anemia identified (eg, iron-, B12-, or folate-deficiency, or anemia associated with CKD). Findings from the current study may be related, in part, to how well practitioners in the study nursing homes evaluated and appropriately targeted therapy to the specific type of anemia rather than empirically prescribing therapy without evaluating the cause of anemia when possible.

Artz et $\mathrm{al}^{3}$ found that while anemia is common in nursing homes, directed therapy for this condition appears to not be common. In their study, although $48 \%$ of residents were found to be anemic, only $2.9 \%$ of all evaluable residents received an ESA, and only $2.3 \%$ received a red blood cell transfusion. These authors concluded that while this low usage may be appropriate, "the reported finding of reduced quality of life and other adverse, clinically important outcomes in anemic, elderly individuals would suggest that the treatment of anemia needs to be considered." The small number of ESA therapy users identified in the current study reaffirms the findings of Artz et $\mathrm{al}^{3}$ regarding the low usage of these agents. Further, the current study also revealed a relatively low rate of utilization for the traditional vitamin supplementation or iron pharmacotherapy among the anemic residents; only half of anemic residents had used vitamin B12, folic acid, or iron. For those anemic residents using any therapy, iron is the mainstay of treatment. It generally appears to be used alone as monotherapy for anemia. However, it is also true that in many patients, a comprehensive evaluation of anemia does not reveal a specific cause. Anemia may be due to chronic inflammation, myelodysplastic syndrome, or occult malignancy.

For ESA therapy users, iron usage is particularly important for effective stimulation of hemoglobin production in patients with low serum ferritin. For instance, iron deficiency is found in $25 \%-37.5 \%$ of all patients with CKD. ${ }^{13}$ In the current study, iron was used by two of every three EPO users, and by one of every three DARB users, though the low resident count in the latter group may explain the low concurrency rate. 
Table 3 Logistic regression model for falls

\begin{tabular}{|c|c|c|c|c|c|}
\hline & Odds ratio & $\begin{array}{l}95 \% \text { lower } \\
\text { bound }\end{array}$ & $\begin{array}{l}95 \% \text { upper } \\
\text { bound }\end{array}$ & $P$ value & $95 \% \mathrm{Sig}^{\mathrm{a}}$ \\
\hline \multicolumn{6}{|l|}{ Demographics } \\
\hline \multicolumn{6}{|l|}{ Age category } \\
\hline$<65$ years & Reference & & & & \\
\hline $65-74$ years & 1.48 & 0.46 & 4.77 & 0.511 & \\
\hline $75-84$ years & 2.64 & 0.89 & 7.85 & 0.081 & \\
\hline $85+$ years & 2.80 & 0.94 & 8.30 & 0.064 & \\
\hline Female & 1.02 & 0.63 & 1.67 & 0.927 & \\
\hline African-American & 1.30 & 0.71 & 2.36 & 0.392 & \\
\hline \multicolumn{6}{|l|}{ Mobility } \\
\hline ADL score & 0.97 & 0.95 & 1.00 & 0.094 & \\
\hline Balance score & 0.94 & 0.82 & 1.06 & 0.312 & \\
\hline \multicolumn{6}{|l|}{ Labs: hemoglobin and renal function } \\
\hline \multicolumn{6}{|l|}{ Hemoglobin level } \\
\hline $13+g / d L$ & Reference & & & & \\
\hline 12 to $<13 \mathrm{~g} / \mathrm{dL}$ & 2.18 & 1.11 & 4.27 & 0.024 & * \\
\hline II to $<12 \mathrm{~g} / \mathrm{dL}$ & 2.10 & 1.01 & 4.40 & 0.048 & * \\
\hline 10 to $<11 \mathrm{~g} / \mathrm{dL}$ & 3.58 & 1.67 & 7.69 & 0.001 & $*$ \\
\hline$<10 \mathrm{~g} / \mathrm{dL}$ & 3.54 & 1.45 & 8.65 & 0.006 & $*$ \\
\hline Low eGFR (MDRD), & 1.04 & 0.67 & 1.62 & 0.872 & \\
\hline \multicolumn{6}{|l|}{$<60 \mathrm{~mL} / \mathrm{min} / \mathrm{l} .73 \mathrm{~m}^{2}$} \\
\hline \multicolumn{6}{|l|}{ Diseases and conditions } \\
\hline Chronic kidney disease & 1.67 & 0.93 & 3.00 & 0.088 & \\
\hline Congestive heart failure & 0.98 & 0.63 & 1.52 & 0.920 & \\
\hline Coronary heart disease & 0.79 & 0.48 & 1.32 & 0.370 & \\
\hline Diabetes (including insulin-dependent) & 0.88 & 0.57 & 1.36 & $0.56 \mathrm{I}$ & \\
\hline Hypertension & 1.17 & 0.71 & 1.93 & 0.528 & \\
\hline Hypotension & 1.45 & 0.33 & 6.33 & 0.621 & \\
\hline Cerebral vascular disease & 0.84 & 0.53 & 1.33 & 0.455 & \\
\hline Peripheral vascular disease & 0.60 & 0.20 & 1.81 & 0.367 & \\
\hline Dementia & 1.03 & 0.66 & 1.60 & 0.900 & \\
\hline Cancer & 0.82 & 0.39 & 1.73 & 0.605 & \\
\hline Parkinson's disease & 1.34 & 0.58 & 3.10 & 0.498 & \\
\hline COPD & 1.19 & 0.74 & 1.92 & 0.467 & \\
\hline Asthma & 1.03 & 0.32 & 3.29 & 0.966 & \\
\hline Osteoarthritis & 0.80 & 0.51 & 1.24 & 0.320 & \\
\hline Rheumatoid arthritis & 1.06 & 0.44 & 2.56 & 0.904 & \\
\hline Neurological disease & 1.03 & 0.57 & 1.84 & 0.927 & \\
\hline \multicolumn{6}{|l|}{ Current medications } \\
\hline Diuretic use & 1.25 & 0.78 & 1.99 & 0.351 & \\
\hline Psychoactive medication use ${ }^{b}$ & 2.01 & 1.26 & 3.23 & 0.004 & $*$ \\
\hline Beta blocker use & 1.16 & 0.74 & 1.82 & 0.519 & \\
\hline \multicolumn{6}{|l|}{ Anemia therapy } \\
\hline Vitamin BI2 (cyanocobalamin) & 1.24 & 0.68 & 2.24 & 0.485 & \\
\hline Folic acid & 1.81 & 0.86 & 3.78 & 0.117 & \\
\hline Iron & 0.83 & 0.51 & 1.33 & 0.434 & \\
\hline DARB or EPO & 0.46 & 0.21 & 1.01 & 0.052 & \\
\hline Propensity to receive DARB or EPO & 1.95 & 0.18 & 20.86 & 0.580 & \\
\hline
\end{tabular}

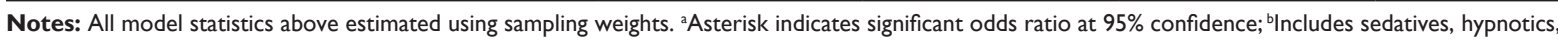
antidepressants, antipsychotics.

Abbreviations: ADL, activities of daily living; COPD, chronic obstructive pulmonary disease; DARB, darbepoetin; eGFR, estimated glomerular filtration rate; EPO, epoetin alfa; MDRD, Modification of Diet in Renal Disease.

Joint guidelines on the prevention of falls in older persons have been issued by the American Geriatrics Society and British Geriatrics Society (AGS/BGS) ${ }^{24}$ According to these guidelines, “ $\ldots$ risk factors associated with falling among persons residing in this setting are similar to factors identified among community-living older adults and include impairments in strength, balance, gait, vision, and cognition; use of multiple medications, especially psychoactive medications; and environmental hazards." These guidelines suggest that " $(\mathrm{m})$ ultifactorial/multicomponent interventions 
Table 4 Logistic regression model for recurrent falls

\begin{tabular}{|c|c|c|c|c|c|}
\hline & Odds ratio & $\begin{array}{l}95 \% \text { lower } \\
\text { bound }\end{array}$ & $\begin{array}{l}95 \% \text { upper } \\
\text { bound }\end{array}$ & $P$ value & $95 \% \mathrm{Sig}^{\mathrm{a}}$ \\
\hline \multicolumn{6}{|l|}{ Demographics } \\
\hline \multicolumn{6}{|l|}{ Age category } \\
\hline$<65$ years & Reference & & & & \\
\hline $65-74$ years & 5.62 & 0.46 & 68.81 & 0.176 & \\
\hline $75-84$ years & 14.84 & 1.31 & 168 & 0.030 & $*$ \\
\hline $85+$ years & 14.25 & 1.27 & 160 & 0.031 & $*$ \\
\hline Female & 0.61 & 0.32 & 1.16 & 0.128 & \\
\hline African-American & 1.02 & 0.47 & 2.20 & 0.959 & \\
\hline \multicolumn{6}{|l|}{ Mobility } \\
\hline ADL score & 0.99 & 0.95 & 1.03 & 0.656 & \\
\hline Balance score & 0.84 & 0.71 & 0.99 & 0.040 & $*$ \\
\hline \multicolumn{6}{|l|}{ Labs: hemoglobin and renal function } \\
\hline \multicolumn{6}{|l|}{ Hemoglobin level } \\
\hline $13+g / d L$ & Reference & & & & \\
\hline 12 to $<13 \mathrm{~g} / \mathrm{dL}$ & 2.84 & 1.03 & 7.82 & 0.043 & $*$ \\
\hline II to $<12 \mathrm{~g} / \mathrm{dL}$ & 2.21 & 0.78 & 6.31 & 0.136 & \\
\hline 10 to $<11 \mathrm{~g} / \mathrm{dL}$ & 4.74 & 1.65 & 13.58 & 0.004 & $*$ \\
\hline$<10 \mathrm{~g} / \mathrm{dL}$ & 3.36 & 1.03 & 11.01 & 0.045 & $*$ \\
\hline Low eGFR (MDRD), & 1.14 & 0.64 & 2.03 & 0.645 & \\
\hline \multicolumn{6}{|l|}{$<60 \mathrm{~mL} / \mathrm{min} / 1.73 \mathrm{~m}^{2}$} \\
\hline \multicolumn{6}{|l|}{ Diseases and conditions } \\
\hline Chronic kidney disease & 2.23 & 1.08 & 4.61 & 0.031 & $*$ \\
\hline Congestive heart failure & 0.66 & 0.36 & 1.19 & 0.162 & \\
\hline Coronary heart disease & 1.26 & 0.66 & 2.38 & 0.485 & \\
\hline Diabetes (including insulin-dependent) & 1.00 & 0.56 & 1.78 & 0.997 & \\
\hline Hypertension & 0.93 & 0.46 & 1.85 & 0.830 & \\
\hline Hypotension & 0.54 & 0.03 & 11.53 & 0.692 & \\
\hline Cerebral vascular disease & 0.66 & 0.35 & 1.28 & 0.219 & \\
\hline Peripheral vascular disease & 0.37 & 0.07 & 2.12 & 0.266 & \\
\hline Dementia & 0.55 & 0.28 & 1.07 & 0.077 & \\
\hline Cancer & 0.96 & 0.33 & 2.74 & 0.935 & \\
\hline Parkinson's disease & 1.74 & 0.59 & 5.14 & 0.318 & \\
\hline COPD & 1.12 & 0.59 & 2.11 & 0.736 & \\
\hline Asthma & 1.50 & 0.38 & 5.93 & 0.561 & \\
\hline Osteoarthritis & 1.21 & 0.66 & 2.22 & 0.538 & \\
\hline Rheumatoid arthritis & 2.13 & 0.71 & 6.32 & 0.175 & \\
\hline Neurological disease & 1.12 & 0.50 & 2.53 & 0.783 & \\
\hline \multicolumn{6}{|l|}{ Current medications } \\
\hline Diuretic use & 1.18 & 0.63 & 2.22 & 0.607 & \\
\hline Psychoactive medication use $\mathrm{b}^{\mathrm{b}}$ & 2.58 & 1.22 & 5.46 & 0.013 & $*$ \\
\hline Beta blocker use & 0.98 & 0.56 & 1.73 & 0.958 & \\
\hline \multicolumn{6}{|l|}{ Anemia therapy } \\
\hline Vitamin BI2 (cyanocobalamin) & 1.19 & 0.55 & 2.57 & 0.664 & \\
\hline Folic acid & 1.32 & 0.53 & 3.28 & 0.548 & \\
\hline Iron & 0.80 & 0.43 & 1.49 & 0.486 & \\
\hline DARB or EPO & 0.06 & 0.01 & 0.30 & 0.001 & $*$ \\
\hline Propensity to receive DARB or EPO & 9.26 & 0.51 & 168 & 0.132 & \\
\hline
\end{tabular}

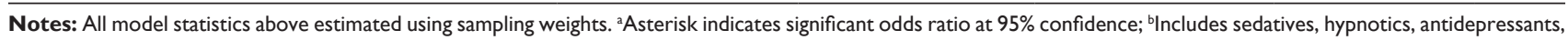
antipsychotics.

Abbreviations: ADL, activities of daily living; COPD, chronic obstructive pulmonary disease; DARB, darbepoetin; eGFR, estimated glomerular filtration rate; EPO, epoetin alfa; MDRD, Modification of Diet in Renal Disease.

should be considered in long-term care to reduce falls," but note that such evidence is "too close to justify a general recommendation". ${ }^{24}$

As suggested in the AGS/BGS guidelines, ${ }^{24}$ findings from the current study reveal that a number of factors in the nursing home setting appear related to falls and recurrent falls. Despite the relatively low number of DARB and EPO users, a reduced odds of recurrent falls (Table 4 ) was observed for the DARB/EPO cohort; a similar finding was noted within the subset of residents with apparent chronic kidney 
Table 5 Logistic regression model for falls and recurrent falls: subpopulation of residents with apparent chronic kidney disease

\begin{tabular}{|c|c|c|c|c|c|}
\hline & Odds ratio & $\begin{array}{l}95 \% \text { lower } \\
\text { bound }\end{array}$ & $\begin{array}{l}95 \% \text { upper } \\
\text { bound }\end{array}$ & $P$ value & 95\% Sig \\
\hline \multicolumn{6}{|c|}{ Subpopulation with eGFR } \\
\hline \multicolumn{6}{|c|}{$($ MDRD $)<60 \mathrm{~mL} / \mathrm{min} / \mathrm{l} .73 \mathrm{~m}^{2}$ or } \\
\hline \multicolumn{6}{|c|}{ MDS Section I chronic kidney disease } \\
\hline \multicolumn{6}{|c|}{ (checkbox or ICD-9 entry) } \\
\hline \multicolumn{6}{|c|}{ Falling } \\
\hline Vitamin BI2 & 1.82 & 0.78 & 4.26 & 0.167 & \\
\hline Folic acid & 2.05 & 0.67 & 6.27 & 0.208 & \\
\hline Iron & 0.81 & 0.41 & 1.60 & 0.548 & \\
\hline DARB or EPO & 0.64 & 0.24 & 1.70 & 0.369 & \\
\hline \multicolumn{6}{|c|}{ Recurrent falling } \\
\hline Vitamin BI2 & 1.65 & 0.50 & 5.45 & 0.410 & \\
\hline Folic acid & 1.18 & 0.32 & 4.37 & 0.803 & \\
\hline Iron & 0.68 & 0.27 & 1.71 & 0.413 & \\
\hline DARB or EPO & 0.09 & 0.01 & 0.62 & 0.015 & $*$ \\
\hline
\end{tabular}

Notes: Findings from full adjusted models of these subpopulations show odds ratios for anemia therapies only. All model statistics above estimated using sampling weights. ${ }^{a}$ Asterisk indicates significant odds ratio at $95 \%$ confidence.

Abbreviations: DARB, darbepoetin; eGFR, estimated glomerular filtration rate; EPO, epoetin alfa; MDRD, Modification of Diet in Renal Disease; MDS, Minimum Data Set.

disease (Table 5). Other covariates, used for adjustment in these models, were also found to be significantly related to the falls or recurrent fall outcomes. As expected, a lower $\mathrm{Hb}$ level was associated with both falls and recurrent falls, with the odds of experiencing either outcome increasing by more than double for those with Hb levels 12 to $<13 \mathrm{~g} / \mathrm{dL}$ or 11 to $<12 \mathrm{~g} / \mathrm{dL}$ when compared to the nonanemic $13+$ $\mathrm{g} / \mathrm{dL}$ reference, and increasing approximately three to five times for those with $\mathrm{Hb}$ levels 10 to $<11 \mathrm{~g} / \mathrm{dL}$ and $<10 \mathrm{~g} / \mathrm{dL}$ when compared to the same nonanemic reference. Use of psychoactive medication remained an independent factor strongly associated with both falls and recurrent falls. Advanced age ( $>75$ years) showed a substantially strong association with recurrent falls. Having a diagnosis of CKD was also strongly and significantly associated with recurrent falls, but not with falls; however, low eGFR had no apparent association with falls or recurrent falls; these two measures of kidney function exhibited only low-to-moderate correlation (Cramer's V correlation coefficient $=0.31$ ) and were thus both retained in each model.

In the current analysis, two measures of mobility were included as model covariates: ADL score and balance score, where lower scores indicated better functioning. Of these, only better balance score was associated with significantly lower odds of recurrent falls, but not with falls. Chaves et $\mathrm{al}^{25}$ had observed that higher $\mathrm{Hb}$ level was associated with better mobility functioning in community-dwelling older women. The current study did not identify an independent association between ADL functioning and either falls or recurrent falls when anemia therapy was considered in the model.
As described earlier, anemia is common in CKD patients. The strong relationship between CKD and age indicates that anemia is an increasingly prevalent problem in long-term care facilities. ${ }^{17,18,26}$ Recent investigational studies evaluating the use of ESAs to target $\mathrm{Hb}$ values greater than $12 \mathrm{~g} / \mathrm{dL}$ have highlighted the potential risks of attempting to treat patients with higher Hb levels. ${ }^{27-32} \mathrm{~A}$ black box warning on all ESAs marketed in the US emphasizes these risks, as well as the appropriate use of these agents in the CKD, cancer, and perisurgery populations..$^{17,18}$

This study had several limitations. First, due to the limited 6-month follow-up and possibility that some residents may have been lost to follow-up if discharged or transferred with no readmission into the facility, associations between falls or recurrent falls with anemia therapies, hemoglobin levels, conditions, and other resident characteristics cannot be assumed as causal. Second, the index $\mathrm{Hb}$ level and serum creatinine levels used to derive covariates in these models may have preceded a falling event by up to 6 months and may not have reflected actual blood levels that would have been available immediately prior this falling event. Thus, neither the chronicity nor the cause of anemia was determined. Third, nurses employed within the nursing homes studied conducted the sampling and chart abstraction. These data abstractors were provided with detailed printed instructions and standardized data collection forms. However, other than observations regarding missing values, the quality and accuracy of data obtained through this process could not be assessed. Fourth, the validity and completeness of medical conditions captured through chart review were not ascertained. In addition, some falls may have been entirely due to an environmental factor 
rather than a factor or factors intrinsic to the patient. Our study was not designed to capture this information. Finally, this retrospective study design considered the relationship of each individual therapy to falls and did not evaluate the interactive effects of therapies when used in combination. Inclusion of the several covariates selected for the logistic regression models, including $\mathrm{Hb}$ level and the propensity to receive EPO, helped to adjust for much of the confounding, but the specific resident conditions for which each therapy was used may not be separable from the therapies studied (eg, vitamin B12 treats pernicious anemia while iron is typically used to treat anemia due to iron deficiency).

\section{Conclusion}

After adjusting for hemoglobin level and other covariates, the current analysis found little evidence to support an association between the use of vitamin B12, folic acid, or iron in reducing the rates of falls and recurrent falls among nursing home residents. Despite the small sample sizes of DARB and EPO users, DARB or EPO use was observed to have a lower adjusted odds ratio of recurrent falls. Further study is warranted to investigate whether these same findings can be replicated in other nursing home populations and whether improvement of anemia-related outcomes is associated with use of ESA or the traditional vitamin B12, folic acid, or iron therapies in this setting. Further research, particularly a prospective study, is also needed to understand whether ESA use leads to improvement in $\mathrm{Hb}$ level in nursing home residents and whether this improvement in turn causes a decline in expected falls or recurrent falls.

\section{Acknowledgement/disclosure}

The current study was sponsored by Janssen Scientific Affairs, LLC. Research data used in this study were collected by Synovate Healthcare and de-identified prior to release for research. At the time this research was conducted, author RAB was an employee of Janssen Scientific Affairs, LLC (a Johnson and Johnson company) and shareholder of Johnson and Johnson, and GR and NP were consultants to Janssen Scientific Affairs, LLC (a Johnson and Johnson company). All authors were involved in conception and design of this study, interpretation of findings, and in drafting the manuscript and/or revising it critically. All authors read and approved the final manuscript. Ruchi Rastogi, employed in the Medical Writing Group at Janssen Services, LLC, provided editorial comments on the author-prepared manuscript.

\section{References}

1. World Health Organization. de Benoist B, McLean E, Egli I, Cogswell M, editors. Worldwide prevalence of anaemia 1993-2005: WHO global database on anaemia. Geneva, Switzerland: World Health Organization; 2008.

2. Kalchthaler T, Tan ME. Anemia in institutionalized elderly patients. J Am Geriatr Soc. 1980;28(3):108-113.

3. Artz AS, Fergusson D, Drinka PJ, et al. Prevalence of anemia in skilled-nursing home residents. Arch Gerontol Geriatr. 2004;39(3): 201-206.

4. Pandya N, Bookhart B, Mody SH, Funk Orsini PA, Reardon G. Study of anemia in long-term care (SALT): prevalence of anemia and its relationship with the risk of falls in nursing home residents. Curr Med Res Opin. 2008;24(8):2139-2149.

5. Robinson B, Artz AS, Culleton B, Critchlow C, Sciarra A, Audhya P. Prevalence of anemia in the nursing home: contribution of chronic kidney disease. J Am Geriatr Soc. 2007;55(10):1566-1570.

6. De Maria R, Ripamonti V, Sandri R, Ceretti AP, Ferratini M. The negative prognostic synergism of anemia and heart disease in female nursing home residents. Am J Cardiol. 2005;96(10):1460-1462.

7. Kiely DK, Flacker JM. Resident characteristics associated with mortality in long-term care nursing homes: is there a gender difference? $\mathrm{J} \mathrm{Am}$ Med Dir Assoc. 2000;1(1):8-13.

8. van Dijk PT, Mehr DR, Ooms ME, et al. Comorbidity and 1-year mortality risks in nursing home residents. J Am Geriatr Soc. 2005;53(4): 660-665.

9. Berry SD, Samelson EJ, Bordes M, Broe K, Kiel DP. Survival of aged nursing home residents with hip fracture. J Gerontol A Biol Sci Med Sci. 2009;64(7):771-777.

10. Rubenstein LZ, Josephson KR, Robbins AS. Falls in the nursing home. Ann Intern Med. 1994;121(6):442-451.

11. Dharmarajan TS, Norkus EP. Mild anemia and the risk of falls in older adults from nursing homes and the community. $\mathrm{J} \mathrm{Am} \mathrm{Med} \mathrm{Dir} \mathrm{Assoc.}$ 2004;5(6):395-400.

12. Artz AS, Fergusson D, Drinka PJ, et al. Mechanisms of unexplained anemia in the nursing home. J Am Geriatr Soc. 2004;52(3): $423-427$.

13. Agarwal AK. Practical approach to the diagnosis and treatment of anemia associated with CKD in elderly. J Am Med Dir Assoc. 2006; 7(Supp1 9):S7-S12.

14. Balducci L. Epidemiology of anemia in the elderly: information on diagnostic evaluation. J Am Geriatr Soc. 2003;51(3 Suppl):S2-S9.

15. Aslinia F, Mazza JJ, Yale SH. Megaloblastic anemia and other causes of macrocytosis. Clin Med Res. 2006;4(3):236-241.

16. Germain MJ. Strategies for successfully managing the anemia of chronic kidney disease in the long-term care setting. Consult Pharm. 2008;23 Suppl A:11-17.

17. Aranesp ${ }^{\circledR}$ (darbepoetin alfa) injection, for intravenous or subcutaneous use (Full Prescribing Information, Revised June 2011). Available from: http:// pi.amgen.com/united_states/aranesp/ckd/aranesp_pi_hcp_english.pdf. Accessed July 15, 2012.

18. PROCRIT ${ }^{\circledR}$ (epoetin alfa) injection, for intravenous or subcutaneous use (Full Prescribing Information, Revised June 2011). Available from: http://www.procrit.com/sites/default/files/shared/OBI/PI/ ProcritBooklet.pdf. Accessed July 15, 2012.

19. Centers for Disease Control and Prevention. National Nursing Home Survey. http://www.cdc.gov/nchs/nnhs.htm. Accessed July 15, 2012.

20. Levey AS, Greene T, Kusek JW, Beck G. A simplified equation to predict glomerular filtration rate from serum creatinine [abstract]. J Am Soc Nephrol. 2000;11:A0828.

21. Manjunath G, Sarnak MJ, Levey AS. Prediction equations to estimate glomerular filtration rate: an update. Curr Opin Nephrol Hypertens. 2001;10(6):785-792.

22. Carpenter GI, Hastie CL, Morris JN, Fries BE, Ankri J. Measuring change in activities of daily living in nursing home residents with moderate to severe cognitive impairment. BMC Geriatr. 2006;6:7. 
23. American Medical Directors Association (AMDA). Anemia in the long-term care setting. Columbia, Maryland: American Medical Directors Association; 2007.

24. American Geriatrics Society. Prevention of Falls in Older Persons AGS/BGS Clinical Practice Guideline. Available from: http://www. medcats.com/FALLS/frameset.htm. Accessed July 15, 2012.

25. Chaves PH, Ashar B, Guralnik JM, Fried LP. Looking at the relationship between hemoglobin concentration and prevalent mobility difficulty in older women. Should the criteria currently used to define anemia in older people be reevaluated? J Am Geriatr Soc. 2002;50(7):1257-1264.

26. Robinson BE. Epidemiology of chronic kidney disease and anemia. J Am Med Dir Assoc. 2006;7(9 Suppl):S3-S6.

27. Strippoli GF. Effects of the dose of erythropoiesis stimulating agents on cardiovascular events, quality of life, and health-related costs in hemodialysis patients: the clinical evaluation of the dose of erythropoietins (C.E. DOSE) trial protocol. Trials. 2010;11:70.

28. Unger EF, Thompson AM, Blank MJ, Temple R. Erythropoiesis-stimulating agents - time for a reevaluation. $N$ Engl J Med. 2010;362(3): 189-192.
29. Aapro M, Osterwalder B, Scherhag A, Burger HU. Epoetin-beta treatment in patients with cancer chemotherapy-induced anaemia: the impact of initial haemoglobin and target haemoglobin levels on survival, tumour progression and thromboembolic events. Br J Cancer. 2009; 101(12):1961-1971.

30. Singh AK, Szczech L, Tang KL, et al. Correction of anemia with epoetin alfa in chronic kidney disease. $N$ Engl J Med. 2006;355(20): 2085-2098.

31. Pfeffer MA, Burdmann EA, Chen CY, et al. A trial of darbepoetin alfa in type 2 diabetes and chronic kidney disease. $N$ Engl J Med. 2009; 361(21):2019-2032.

32. Clement FM, Klarenbach S, Tonelli M, Johnson JA, Manns BJ. The impact of selecting a high hemoglobin target level on health-related quality of life for patients with chronic kidney disease: a systematic review and meta-analysis. Arch Intern Med. 2009;169(12):1104-1112.
Clinical Interventions in Aging

\section{Publish your work in this journal}

Clinical Interventions in Aging is an international, peer-reviewed journal focusing on evidence-based reports on the value or lack thereof of treatments intended to prevent or delay the onset of maladaptive correlates of aging in human beings. This journal is indexed on PubMed Central, MedLine, the American Chemical Society's 'Chemical Abstracts Ser-

\section{Dovepress}

vice' (CAS), Scopus and the Elsevier Bibliographic databases. The manuscript management system is completely online and includes a very quick and fair peer-review system, which is all easy to use. Visit http://www.dovepress.com/testimonials.php to read real quotes from published authors. 